\title{
Psychological Adaptation to Extreme Environments: Antarctica as a Space Analogue
}

\author{
Tortello Camila ${ }^{1,2}$, Barbarito Marta ${ }^{3}$, Cuiuli Juan Manuel ${ }^{4}$, Golombek Diego ${ }^{2}$, Vigo Daniel E ${ }^{1,5^{*}}$ and Plano \\ Santiago ${ }^{1,2 *}$ \\ ${ }^{1}$ Institute for Biomedical Research (BIOMED), Catholic University of Argentina (UCA)-NationalScientific and Technical Research Council (CONICET), \\ Argentina \\ ${ }^{2}$ Chronobiology Lab, National University of Quilmes (UNQ), Argentina
}

${ }^{3}$ Antarctic Psychology, Argentine Antarctic Institute, Argentina

${ }^{4}$ Argentine Joint Antarctic Command, Argentine Army, Argentina

${ }^{5}$ Faculty of psychology and educational sciences, KU Leuven,Argentina

Submission: June 23, 2018; Published: July 18, 2018

*Corresponding author: Plano Santiago, Institute for Biomedical Research (BIOMED), Catholic University of Argentina (UCA)-National Scientific and Technical Research Council (CONICET), Argentina, Email: Santiago.plano@unq.edu.ar

\begin{abstract}
Space analogues are settings where conditions can be reproduced to study physiological and psychological variables experienced in space. Antarctica is one of the most reliable analogues to assess the effects of isolation, confinement, light-dark cycle and extreme environmental conditions in human being. In the present review we describe some of the aspects of psychological adaptation to extreme latitudes.Most of the studies found some evidence about changes in emotional states during Antarctica expeditions. However, these changes are highly variable, and beneficial as well as detrimental aspects of adaptation have been described. Adaptation to extreme environments is a complex phenomenon that needs multidimensional studies to be fully understood, comprising aspects such as seasonality, psychological traits, isolation conditions and social interactions.
\end{abstract}

\section{Introduction}

Exploring and controlling variables implicated in a spaceflight is one of the most challenging aspects of space science, since space missions provide the only real environment where these studies can be conducted [1]. However, there are terrestrial settings that can be used as analogues to assess factors associated to space exploration. Also known as "space analogues", they are a way to reproduce and study some of the conditions that a subject may deal with in a space mission. There are several scenarios in Earth that might guide us to enrich our knowledge about space challenges and to think about possible interventions to extend human adaptability to them [2-7]. Researchers have centered their attention on different psychological dimensions that can be affected in space modulated by the analogues. Numerous studies focus on the impact of confinement and isolation over psychological variables, describing changes in emotional states caused by these conditions[8-10]. Others propose the importance of light exposure to maintain psychophysiological functions in space [11], as it was observed that it might play a main role in affective disorders [12].With about 14-millon square kilometers covered by thick ice layers, located in the Antarctic Polar Cycle [13], Antarctica is characterized by 24-hours of darkness during winter (polar night) and constant light conditions during summer (Figure 1). Extreme temperature and environmental conditions make Antarctica a tough place to live in. Thus, mostly military personnel and scientific researchers stay in small groups for special expeditions. These characteristics define Antarctica as one of the most reliable space analogues where isolation, confinement, light-dark cycle and extreme environmental conditions can be examined $[8,14,15]$. Mood fluctuations, emotional disruptions and psychological disorders were claimed to be related to some of Antarctica's characteristics already mentioned. One of the most studied disorders associated to changes in dark-light cycle is the seasonal affective disorder (SAD). It is a subtype of depression defined by major depressive episodes during fall or winter months [16]. Many researchers have centered their attention 
in what happens with mental health in the absence of natural light exposure, considering that almost $5 \%$ of the expeditioners meet DSM-IV or ICD criteria for psychiatric disorder like anxiety and depression [17]. Although there are a lot of studies that try to find out the relationship between polar night and emotional states, there is no consensus about the real link between seasonal affective disorder and Antarctica expeditions. Some studies agree to conclude depression symptoms are noticeable during Antarctica winter due mainly to poor sleep, changes in light-dark cycle and psychosocial stress, while others affirm to find decreases in depression and anxiety symptoms along the expedition [17].

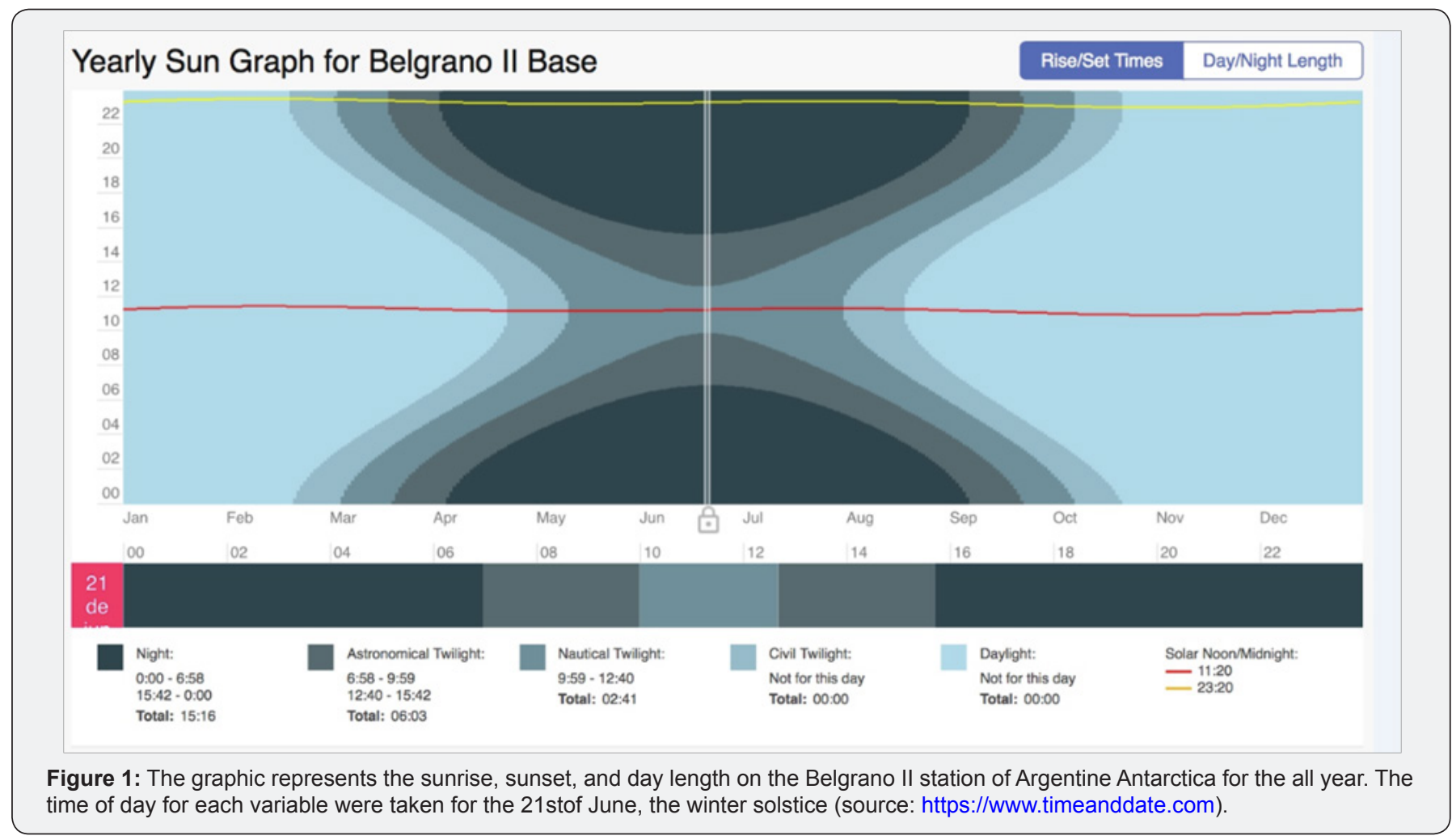

On one hand, moderate findings were achieved regarding the modulation of subject's mood by polar night. After evaluating a crew of 70 men and women which stayed at different Antarctica USA Stations, only one person developed seasonal affective disorder during mid-winter while the prevalence of subsyndromal SAD was of $18 \%$ in the same period [18]. It has been reported, that SAD is associated to circadian rhythms, which are modulated by the light-dark cycle of Antarctica [19]. However, only subsyndromal SAD was evidenced [20], exhibiting increased depression symptoms, sleep disorders, increased appetite, weight gain, fatigue and decreased sociability [21]. Regarding gender differences, females seemed to have more incidence of SAD [22]. Furthermore, studies reported that seasonal changes seemed to modulate other psychological variables, as evidenced by an increase in depressive symptoms[23], hostility, sleep disturbance and a decrease in cognitive performance, configuring the «winter - over syndrome» [17]. In concordance with these results, psychological parameters such as negative affect, tension, anger and confusion also increased during overwintering [21]. Not only seasonality is considered to modulate affection, but also bad weather, which was associated with negative mood fluctuations[24]. Additionally, social variables such as adjustment to a group, monotony environment and absence of emotional satisfaction, appeared to play a main role in the development of psychological stress during isolated Antarctic stays [25].

On the other hand, some studies claim to find nonsignificant or positive results about the influence of Antarctica's conditions over psychological variables. Comparing stress and anxiety levels before and after an Antarctic expedition, psychometric parameters showed higher scores for measures taken immediately before traveling [26]. In addition, depression symptoms, fatigue, anxiety and confusion showed a decline during a three-week expedition demonstrating a good psychological adjustment [27]. In this regard, it was reported that depression diagnoses during winter were not significant, but that symptoms related to this disorder were associated to sleepiness and tiredness [23]. A positive correlation was found between physical activity during the day and evening subjective mood [24]. This result may evidence the importance of the daily routine on achieving positive emotional states. A satisfactory use of coping strategies and the tendency to take advantage of the experience to develop personal maturity was also informed [28]; (Table 1). 


\section{Psychology and Behavioral Science International Journal}

Table 1: Principal findings in Antarctica chronological order.

\begin{tabular}{|c|c|c|}
\hline Year & Finding & Authors \\
\hline 1995 & SAD had more incidence in women $[22]$ \\
\hline 1995 & Define in depression symptoms, fatigue, anxiety and confusion & Palinkas [27] \\
\hline 2001 & Satisfactory use of coping strategies & Steine [26] \\
\hline 2003 & Less stress and anxiety & Mullin [25] \\
\hline 2006 & Psychosocial variables impact on stress $[23]$ \\
\hline 2010 & Depressive symptoms during winter & Arendt J [20] \\
\hline 2012 & Subsyndromal SAD & Anto-solanas[24] \\
\hline 2016 & Bad weather correlated with mood fluctuations & Chen [21] \\
\hline 2016 & gncreased depression symptoms, sleep disorders, appetite, weight \\
\hline 2017 & gain and fatigue & Arendt \&Middelton [19] \\
\hline 1996 & Subsyndromal SAD increased a 18\% during mid-winter & Palinkas LA [33] \\
\hline
\end{tabular}

As it was briefly described, most studies found some evidence about changes in emotional states during Antarctica staying. However, these changes are highly variable, and beneficial as well as detrimental aspects of adaptation have been reported. Thus, extreme conditions are not necessarily related with adverse psychological outcomes. Some limitations of the researches should be considered. In general, samples tend to be small and individual differences can alter conclusions. In some cases, data were registered only during summer [29]. Finally, studies that centered their attention on the influence of extreme photoperiods set aside other main aspects such as group dynamics, interpersonal relations and prolonged confinement and isolation. At the same time, analysis, which spotlight psychosocial characteristics, did not consider the influence of chronobiological changes.

Antarctica is well known as a model to study the impact of darkness in psychological variables, including depression and anxiety symptoms [30]. In addition, other aspects of confinement impact on mental health, including, interpersonal relationship, daily monotony and absence of privacy [21,31-33]. Emotional state in space missions is a complex phenomenon that can be influenced by many individual, interpersonal and contextual variables. In this regard, multidimensional studies are needed to fully understand it, which should include seasonality, psychological traits, confinement and isolation conditions, and psychosocial aspects of crew members interactions. In turn, preventive psychological countermeasures could be developed to improve adaptation to long-duration space missions [8].

\section{Acknowledgement}

This work was supported by the Ministry of Defense through a PIDDEF grant. We wish to thank Graciela Romanelli for her technical assistance.

\section{References}

1. Suedfeld P (1991) Polar psychology: An overview. Environment and Behavior 23(6): 653- 665.

2. Corbett RW, Middleton B, Arendt J (2012) An hour of bright white light in the early morning improves performance and advances sleep and circadian phase during the Antarctic winter. Neuroscience Letters 525 (2): 146-151.

3. Lieberman P, Morey A, Hochstadt J, Larson M, Mather S (2005) Mount everest: A space analogue for speech monitoring of cognitive deficits and stress. Aviat Space Environ Med 76(6): B198-B207.

4. Crucian B, Simpson RJ, Raymond, Mehta S, Stowe R, et al. (2014) Terrestrial stress analogs for spaceflight associated immune system dysregulation. Brain Behavior Immunity 39: 23-32.

5. Palinkas LA, Houseal M (2000) Stages of change in mood and behavior during a winter in Antarctica. Environment and Behavior 32(1): 128141.

6. Van Broock L, De León P, Vigo DE (2015) Integrated planetary outpost simulation to assess crew psychophysiological response as a first approach to a lunar/mars manned base settlement. American Journal of Medical and Biological Research 3(4): 107-112.

7. Vigo DE, Tuerlinckx F, Ogrinz B, Wan L, Simonelli G, et al. (2013) Circadian rhythm of autonomic cardiovascular control during mars 500 simulated mission to mars. Aerospace Medical Association 84(10): 1023-1028.

8. Nicolas M, Suedfeld P, Weiss K, Gaudino M (2016) Affective, social and cognitive outcomes during a 1-year wintering in Concordia. Environment and Behavior 48(8): 1073-1091.

9. Palinkas L (2001) Mental and cognitive performance in the cold. International Journal of Circumpolar Health 60(3): 430-439.

10. Norris (2017) Play building as qualitative research: A participatory arts-based approach. Routledge, USA.

11. Dijk DJ, Neri DF, Wyatt JK, Ronda JM, Riel E (2001) Sleep, performance, circadian rhythms and light-dark cycles during two space shuttle flights. American Journal of Physiology-Regulatory, Integrative and Comparative Physiology 281(5): 1647-1664. 
12. Pääkkönen T, Leppäluoto J, Mäkinen TM, Rintamäki H, Ruokonen A (2008) Seasonal levels of melatonin, thyroid hormones, mood and cognition near the arctic circle. Aviation, Space and Environmental Medicine 79(7): 695-699.

13. Mehlhorn B, Mehlhorn H (2017) Antarctica: The peculiar world. Biodiversity and Evolution of Parasitic Life in the Southern Ocean, Springer, pp. 7-12.

14. Lugg D, Shepanek M (1999) Space analogue studies in antarctica. Acta Astronautica 44(7-12): 693-699.

15. Suedfeld P, Weiss K (2000) Antarctica: Natural laboratory and space analogue for psychological research. Environ Behav 32(1): 7-17.

16. Rohan KJ, Rough JN (2017) Seasonal affective disorder. The Oxford Handbook of Mood Disorders 254.

17. Palinkas LA, Suedfeld P (2008) Psychological effects of polar expeditions. Lancet 371(9607): 153-163.

18. Palinkas LA, Wingard DL, Barrett Connor E (1996) Depressive symptoms in overweight and obese older adults: a test of the "jolly fat" hypothesis. Journal of psychosomatic research 40(1): 59-66.

19. Arendt J, Middelton B (2018) Human seasonal and circadian studies in Antarctica (Halley, $75^{\circ} \mathrm{S}$ ). General and comparative endocrinology 258: 250-258.

20. Arendt J (2012) Biological rhythms during residence in polar regions. Chronobiol Int 29(4): 379-394.

21. Chen N, Wu Q, Li H, Zhang T, Xu C (2016) Different adaptations of chinese winter-over expeditioners during prolonged Antarctic and sub-Antarctic residence. International journal of biometeorology 60(5): 737-747.

22. Levine ME (1995) Seasonal symptoms in the sub-Arctic. Mi Med 160(3): 110-114.

23. Harris A, Marquis P, Eriksen HR, Grant I, Corbett R (2010) Diurnal rhythm in British Antarctic personnel. Rural Remote Health 10(2): 1351.
24. Anton Solanas A, O’Neill BV, Morris TE, Dunbar J (2016) Physiological and cognitive responses to an antarctic expedition: A Case Report. International Journal of Sports Physiology and Performance 11(8): 1053-1059.

25. Mullin JR (2006) Some psychological aspects of isolated Antarctic living. American Journal of Psychiatry 117(4): 323-325.

26. Steine S, Steine K, Sandbaek G, Røseth AG (2003) A polar expedition in challenging circumstances experiences and psychological reactions. Tidsskr Nor Laegeforen 123(24): 3524-3528.

27. Palinkas LA, Cravalho M, Browner D (1995) Seasonal variation of depressive symptoms in Antarctica. Acta Psychiatrica Scandinavica 91(6): 423-429.

28. Barbarito M, Baldanza S, Peri A (2001) Evolution of the coping strategies in an isolated group in an Antarctic base. Polar record 37(201): 111-120.

29. Khandelwal S, Bhatia A, Mishra AK (2015) Psychological health in the summer team of an Indian expedition to Antarctica. Journal of Mental Health and Human Behaviour 20(2): 65-70.

30. Mocellin JS, Suedfeld P, Bernadelz JP, Barbarito ME (1991) Levels of anxiety in polar environments. Journal of Environmental Psychology 11(3): 265-275.

31. Palinkas LA (2003) The psychology of isolated and confined environments: Understanding human behavior in Antarctica. American Psychologist 58(5): 353-363.

32. Peri A, Scarlata C, Barbarito M (2000) Preliminary studies on the psychological adjustment in the Italian Antarctic summer campaigns. Environment and Behavior 32(1): 72-83.

33. Tanaka M (1997) Group structure and its development in an isolated and confined environment. Environmental Medicine: Annual Report of the Research Institute of Environmental Medicine, Nagoya University, Japan, 41(2): 131-134.

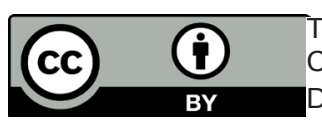

This work is licensed under Creative Commons Attribution 4.0 License DOI: 10.19080/PBSIJ.2018.09.555768

\section{Your next submission with Juniper Publishers will reach you the below assets}

- Quality Editorial service

- Swift Peer Review

- Reprints availability

- E-prints Service

- Manuscript Podcast for convenient understanding

- Global attainment for your research

- Manuscript accessibility in different formats

( Pdf, E-pub, Full Text, Audio)

- Unceasing customer service

Track the below URL for one-step submission https://juniperpublishers.com/online-submission.php 